\title{
Choral Singing and Wellbeing: Findings from a Survey of the Mixed-Chorus Experience from Music Students of the University of Education Winneba, Ghana
}

\author{
Emmanuel Obed Acquah \\ Senior Lecturer, Department of Music Education \\ University of Education, Winneba, Ghana \\ eoacquah@uew.edu.gh
}

Received: June 22, 2016 / Accepted: September 28, 2016 / Published: December 16, 2016

\begin{abstract}
Choral singing, termed 'mixed chorus', is an integral part of the academic activities of the Department of Music Education, University of Education, Winneba. However, the impact of the singing on the wellbeing of the students and lecturers is largely unexplored. With 350 participants, this study contributes to filling that gap. Using questionnaire and interviews, the article examines the health benefits of singing in terms of emotional, psychological, social and physical wellbeing. It concludes that the mixed chorus has a great impact on the total health of the participants. However, this impact is dependent on some generative mechanisms needed in the training of choral singers.
\end{abstract}

Keywords: $\quad$ singing, wellbeing, mixed chorus, University of Education, Winneba (UEW), generative mechanisms

Public health professionals and researchers are increasingly giving serious consideration to the idea that the fitness and wellbeing of individuals, institutions and communities are dependent on multiple factors that call for collaboration across and within sectors. This is probably due to the redefinition of health by the World Health Organisation (1946) which recognises freedom of choice and emphasizes the role of individuals and communities in defining what health means to them. Epp (1987) comments on this new perspective of health from a broad range of factors, such as human biology, lifestyle, the organisation of health care, and the social and physical environments in which people live:

Health ceases to be measurable strictly in terms of illness and death. It becomes a state which individuals and communities alike strive to achieve, maintain or regain, and not something that comes about merely as a result of treating and curing illnesses and injuries. It is a basic and dynamic force in our daily lives, influenced by our circumstances, our beliefs, our culture and our social, economic and physical environments. (p. 420)

Given the dynamic force of health in our daily lives, there is the need to examine other possible activities and circumstances that facilitate the wellbeing of the people. It is for this reason that this study is undertaken to explore the extent to which choral singing can be one of such broad factors for solving contemporary problems relating to health and wellbeing. 
Indeed, the effect of music on the emotional, psychological, social and physical wellbeing of performers and even listeners is quite remarkable. Music provides self-acceptance, sense of purpose or fulfilment in life, impression of continued growth or feeling of interpersonal connectedness, happiness and subjective wellness which Schmutte and Ryff (1997) describe as common strands in psychological wellbeing. If choral singing has the potential to positively affect the health and the total wellbeing of people, then it is very important in our lives. Choral singing, for instance, permeates the musical cultures that are cultivated and performed all over Ghana. This is seen from the proliferation of youth choirs and other choral groups across the country (Amuah \& Acquah, 2013). Many different curricular programs in Ghana's music institutions also attach particular importance to the correct and proper use of the voice as a means of expression. As a result, the Department of Music Education of the University of Education, Winneba in Ghana, organises choral singing, termed 'mixed chorus', ${ }_{1}^{1}$ three times in a week during the semester to provide all students with the opportunity to experience choral singing. The mixed chorus sessions are led by lecturers who design strategies of training and decide on the repertoire to be used in order to ensure proper and effective singing during the performance.

The role of singing in our communities has become pervasive because it continues to be used for many purposes, including advertisement on the radio and television. Generally, it is known that singing does not only accompany church liturgies and rites of passage in Ghana but also promotes nationalistic and local pride through national anthems, team loyalty and support at sporting events. Socially, it facilitates romance during courtship and bestows a sense of individual spirituality (Hays \& Minichiello, 2005; Storr, 1992). Several research works have been conducted on choral music, with the scholarly objective of demonstrating the healing capability of this creative genre. For instance, Aldridge (1996), Winter, Paskin and Baker (1994), Maranto (1993) and White (1992) report on how choral music helps in reducing stress, anxiety, depression, helplessness and low self-esteem by enhancing the function of the immune system. Music does not just evoke imagery and associations, it can also elicit physiological and psychological responses (Tomatis, 1991), alter the perception of chronic pain (Rider 1987; Schorr, 1993), soothe the soul of restless people and assist them to engage in social activities such as dancing and clapping to perform daily routines (Bunt, 1996; Davis, 1999) and assist in forming friendship and social networks (Kahn, 2001; Blacking, Byron \& Nettl, 1995). Bright (1995) also stresses how music elicits cognitive, physical and emotional responses.

The idea behind the institution of the mixed chorus in the Department of Music Education may not be due to any of these healing effects; it is rather a requisite part of the musical training of all students in the Department. As Ahmet (2015, p. 879) argues, 'Choral training is the most fundamental, effective and widely studied field in Music Education'. Moreover, choral education does not only teach culture and love of music but also allows a large number of people to study and train together (Eguz, 1981). Inasmuch as students are professionally trained in this department, it is imperative that choral training becomes part of their academic program. This is because it is one of the ways to develop their musicianship and hone their skills in musical interpretations. It is worth stating that there are other benefits that the performers and trainers gain, in terms of emotional, social, psychological and physical wellbeing, which are not consciously known. Some questions then come to mind: Is there any therapeutic effect of the mixed chorus experience? How can the mixed chorus be strengthened to ensure the total wellbeing of the performers and trainers? Although questions relating to singing and its benefits have been widely addressed by scholars (Small, 2011; Dillon, 2006; Staricoff 2004; Biley

\footnotetext{
${ }^{1} \mathrm{~A}$ term used to refer to choral singing involving men and women
} 
2000), many of these studies have been done outside Ghana. In this paper, I address these questions by discussing the effect of singing on wellbeing in the context of the mixed chorus experience in the Department of Music Education of the University of Education, Winneba, Ghana. In dealing with the subject of this study, I review literature on singing and wellbeing, show the methodology used, present results and discussion, and conclude with suggestions on some generative mechanisms appropriate for choral performance and training that would consequently yield the desired therapeutic benefits. Henfridsson and Bygstad (2013, p. 909) use the term 'generative mechanism' in digital infrastructure to mean 'the causal powers that explain how and why such infrastructure evolves over time'; while Tsoukas $(1989$, p. 551), from the realist line of reasoning, explains the term as 'the causal powers at work independent of the events they generate'. In this study, I use the term to refer to the training techniques and facilitating ideals which are fundamental to good choral singing and its positive effect on health and wellbeing.

\section{Literature Review}

A substantial increase in research relating to music and health has been recorded over the past few years. Some of these investigated how the arts in general, particularly music, have contributed to the health and wellbeing of participants. Scholars, such as Dillon (2006), Staricoff (2004), Lipe (2002), Blood and Zatorre (2001), and Biley (2000), assert that singing and other activities involving music are a fundamental part of human existence. Thus, enjoying and performing music have been recorded since the earliest civilisations. Marek (2007) confirms:

Throughout the history of Western music, vocal music has served as the archetype for musical expression at least in part because many theorists, musicians, and pedagogues embrace the idea that the human voice reaches the deepest feelings of the human spirit. (p. xix)

Though Marek's assertion is in the context of Western music, it addresses a general fact which is very pertinent to the crux of this study. The mixed chorus is undoubtedly vocal and therefore has the potential to make a major contribution towards the general wellbeing of performers and participants. Vocal music contributes towards positive self-esteem, enhances feelings of competence and independence and lessens the experience of social isolation (Hays \& Minichiello, 2005). This is why Amuah and Acquah (2013, p. 111) recommend the need for every youth to participate in choral singing as it is capable of developing the logical thinking and the emotions of individuals. The mixed chorus experience is likely to make a major contribution not only towards professional skills but also the health and wellbeing of participants. This is because singing in the musical arts has often been discussed as a channel for human emotion and expression (Kivy, 2001). Further, the health benefits of musical engagement cut across the age dichotomy (Cohen, Bailey \& Nilsson, 2002). Active participation in singing with the appropriate generative mechanisms is likely to contribute to self-expression and mood enhancement, sense of place and belonging as described by Duffy (2005). Participants in music, and for that matter singing, usually feel accepted, valued and needed, and therefore partake in lifelong learning (Davis, 1999; Kahn, 2001; Small, 2011).

These scholars were not specific whether these benefits are connected with group musicmaking or individual performances. Nonetheless, I believe that they see the need for singing 
and music-making in general. A number of studies on the benefits of singing have been undertaken with diverse samples of singers, and these provide evidence from reports on a range of social, psychological and health benefits associated with singing. Bailey and Davidson (2002/2005), for example, interviewed choir singers from a range of social backgrounds in Canada while Silber (2005) explored the impact of a singing group established in a women's prison in Israel. In the reports of these scholars, they stress the need for everyone to sing. The work of Clift, Hancox, Morrison, Hess, Kreutz and Stewart (2010) is of particular relevance to this study. In their research, 600 choral singers were drawn from English choirs to complete a questionnaire to measure their physical, psychological, social and environmental wellbeing. They provided accounts of the effects of choral singing on quality of life, wellbeing and physical health in response to open questions. Their accounts revealed that singing may impact wellbeing and health positively, especially through focused attention, deep breathing, social support, cognitive stimulation and regular commitment. The discussion in this paper will also focus on the positive outcomes of singing on health and general wellbeing of the performers of mixed chorus in a Ghanaian context. It will also explore the generative mechanisms that could be put in place in the training and performance of singing to create the desired effect.

Bright (1997) has suggested that singing can have an evocative effect on a person's emotions, memories and past connections in life. He further shows how it can be used to facilitate people's enjoyment of shared interests and activities. The author, consequently, justifies music's claim as a branch of preventive medicine. Singing can help in the interpretation of meaning in our lives and provide people with another level and dimension for understanding life experiences (Kenny, 1999). This is because much evidence shows the impact of singing on a wide variety of emotional, physical and spiritual benefits for even those with speech disorders. For instance, Healey, Mallard and Adams (1976) examined whether singing could reduce stuttering. Participants were therefore asked to read or sing the lyrics of songs. The reduction in stuttering was greater in the singing than in the reading condition. The greatest reduction was observed when familiar lyrics were sung. Similarly, Andrews, Howier, Dozsa and Guitar (1982) examined the effects of 15 different fluency-enhancing methods (including singing) on a number of stuttering measures. In the singing condition, participants were asked to sing any song of their choice for 10 minutes. Results showed that singing reduced the frequency of stuttering by over $90 \%$, presumably due to the increased duration of phonation. Further evidence of the benefits of singing in increasing fluency has been shown by Davidow, Bothe, Andreatta and Ye (2009). For this reason, it is significant that the benefits of the mixed chorus are explored and disseminated in order to strengthen bonds of togetherness and sharing because 'one of the primary functions of music, which includes singing, is to enhance the quality of individual experience and human relationships' (Blacking, Byron \& Nettl, 1995, p. 49).

\section{Methodology}

The mixed chorus in the Department of Music Education of the University of Education, Winneba, is organised three times a week for all students in the following programs: the fouryear Bachelor of Music (B.Mus.), four-year Bachelor of Arts (BA) in Music Education, and the two-year Diploma in Music. The mixed chorus is held on Mondays, Tuesdays and Thursdays for one hour from $7.30 \mathrm{a} . \mathrm{m}$. to $8.30 \mathrm{a} . \mathrm{m}$. and it is mandatory for every student, irrespective of their choral background. The choir performs one grand concert almost at the end of every semester to commemorate either the birth or death of Christ. Additionally, during election years, peace concerts, where students in the mixed chorus are required to perform, are sometimes 
organized. As a result, musical pieces used in the chorus are either religious or patriotic in nature.

In finding out the therapeutic benefits of the mixed chorus and how it can be improved, I adopted a descriptive survey method. A survey is a means of 'gathering information about the characteristics, actions or opinions of a large group of people, referred to as population' (Tanur, 1982, p. 77). It became necessary to adopt this method because surveys provide an avenue for more honest and unambiguous responses. Therefore, choosing this research strategy allows for the collection of large amounts of data in an efficient manner (Kotzab, 2005, p. 126). In the current study, this was done using questionnaire and interview.

After the rationale for the study had been explained to them, 345 undergraduate students who were randomly sampled during mixed chorus sessions, were asked to complete a 20-item questionnaire. For the purpose of allowing participants to express their views on how they have benefited therapeutically from the mixed chorus experience, a few of the questions were designed to elicit open-ended responses. Although their general opinion about the mixed chorus were sought, the questionnaire focused on participant's own health, rather than asking about the possible effects of singing on other people's health.

Attention was given to the comments written on the questionnaire by the participants in order to explore the issues addressed by this survey more concretely. More appropriately, responses to some of the open-ended questions were discussed according to the class levels of students in groups created for each class on the social media platform WhatsApp. Personal views on the healing effects were revealed during the discussion.

Three hundred and nineteen participants returned the questionnaire after four followups, which yielded a response rate of $92.4 \%$. In addition, interviews were undertaken with a purposive sample of five lecturers who train the students at mixed chorus sessions. These five lecturers were interviewed to find out how singing affects the emotional, psychological, social and physical wellbeing of the performers and how the mixed chorus can be improved using specific mechanisms. All interviews were conducted in the offices of the lecturers and recorded with their permission and then later transcribed for analysis. The interviews were informal, with the discussion focusing on the benefits of singing on the general wellbeing of the performers and trainers. During the interviews, specific therapeutic and healing values of singing were discussed. This led to the discussion of certain generative mechanisms that could be employed in the training of singers to ensure their total wellbeing.

\section{Results}

Participants indicated a range of significant health-related outcomes for participating in singing. Apart from the acquisition of professional skills, the 20 items were designed to cover some constructs in connection with singing, health and wellbeing. Participants' endorsement of the items ranged from $72 \%$ to $90 \%$. They also reported that they had experienced most of the items on singing and wellbeing from the mixed chorus experience. However, $10 \%$ to $28 \%$ reported that they had not experienced it much, conceding though that the mixed chorus was very important to them in terms of improving their sight reading skills in music. It is actually not surprising that some students benefited less from the mixed chorus because existing literature corroborates the position that large ensemble participation, including choral ensembles, in schools is a positive motivator for some students and also discourages others (Kratus, 2007). It is likely to experience such situations, especially where the mixed chorus ensemble is mandatory, making all students, whether interested in singing or not, to participate in it. Nevertheless, 
most participants indicated how they feel happier with themselves and content at developing relationships with others through the mixed chorus experience.

The singing experience between the students and the lecturers was intensely found to be individualistic and extremely personal for most of them because personal meaning that related to performance practice, social identity, psychological benefit, emotional wellbeing, therapeutic benefit and social wellbeing were expressed idiosyncratically. This includes how singing affects the lives of the performers and how it facilitates connection with life experiences. Others are intellectual stimulus, emotional satisfaction, spiritual growth and capacity building. The results of the study showed that singing has direct links with health and wellbeing, stimulus and motivation. The data further revealed that the mixed chorus is an important part of the lives of the students and the lecturers because it also provides ways for defining and redefining their understanding of emotions, and maintaining personal wellbeing. The following are some few idiosyncratic responses from some of the participants.

Richmond, a level 200 Bachelor of Arts, Music Education student describes his experience in the mixed chorus:

I am a shy person, especially when I see females around. My whole education has been through non-coeducational institutions but I am blessed that this mixed chorus has helped me adjust tremendously. I was almost becoming socially isolated but attending school here to do music and take part in the mixed chorus has lifted my self-esteem, self-belief and social life. I can't really tell how it happened but that is how I feel.

Rita, a level 200 B.Mus. student shares her experience on the WhatsApp platform:

Anytime I have headache and sing together with friends at mixed chorus, my pain vanishes. Experiencing the sounds of harmony peeling through my whole being, my moodiness, as a result of my ill health, flies away.

When asked to give her opinion about the therapeutic benefit of the mixed chorus, Mrs Arko-Mensah, a lecturer of the department and a participant of this study, commented:

In fact, I believe all of us have not really been conscious of the therapeutic benefit of the mixed chorus. All we know is that it is part of our academic training, and it is compulsory for every student but I have my own joyous experience; the satisfaction alone I get from training the students at mixed chorus is a medicine for me. The fulfilment and excitement of singing at chorus cannot be described in words. It is always a soothing moment for me.

Ransford, a Diploma One student, expresses some benefits he has gained from the mixed chorus:

My mother was involved in a terrible accident while my father was incapacitated with stroke. There was no assistance anywhere to pay my school fees and so [I] suddenly suffered from depression. When I finally came to school, beginning the day with mixed chorus, meeting people, laughing along the way of some 
jokes from some of the lecturers, listening and singing in harmony always makes me forget about such situations.

Sylvia, a Level 400 B.Mus. student who had a health challenge, shared her therapeutic experience:

Sir, I was diagnosed of migraine and bleeding ulcer about two years ago. The doctor has advised me not to put too much stress on my brain. The pain I sometimes go through is unbearable and it makes me fall unconscious at times. I therefore find it difficult mingling with people because I can fall down like someone with epilepsy anytime my condition becomes severe. I just therefore avoid people to save me from disgrace in case my condition emerges. I have to be taking expensive drugs to get along but, anytime I attend mixed chorus and sing, my pain subsides and I feel as if nothing was wrong with me. I get hope and feel being part of a big family. As far as I continue to be a student here, mixed chorus is my efficacious medicine.

Each and every participant had something to say and that reflected in their responses to the questionnaire administered to them. The data gathered through interview also revealed that attentiveness, deep breathing, commitment, physical fitness, sharing and brain stimulation are some generative mechanisms which can foster the therapeutic effect of choral singing.

\section{Discussion}

The study showed the tremendous benefits of singing in the lives of the respondents as a greater percentage of them were more articulate about the importance of the mixed chorus and how it had contributed to their wellbeing and quality of their professional growth. The identified themes, which included emotional, psychological, social and physical wellbeing, in connection with singing at the mixed chorus were discussed. While singing at mixed chorus, for some respondents, was just part of an academic exercise, for others, it functioned as a way of sharing and connecting in their lives, linking life events, thereby promoting personal wellbeing. For some it was therapeutic, and for others, it had a strong spiritual significance.

Under emotional effect, participants indicated how the mixed chorus released their tension and relieved them of sadness because it usually uplifted them spiritually. Students stressed that as members of the chorus, they became team players and therefore helped one another by reciprocally offering invaluable strength and support to cope with emotional stress. Sometimes, individual troubles and frustrations were held in check because singing at mixed chorus was predominated with concentration. Nevertheless, the joy of performing with attentiveness, the harmony, the resonance and chord progressions of song, affected the innermost beings and psyches of participants, including the performers and the trainers every time there was performance. Participants explained this, by showing how they reach new heights of being, singing together at the mixed chorus. They further claimed that it was an experience that did not exist outside the frontiers of the University. Participants also stressed that they feel positive during mixed chorus and their mood was raised as the lesson induced positive emotions. Invariably, problems carried from the home were forgotten due to the chorus, thereby improving their selfconfidence. 
Psychologically, the mixed chorus involves education and learning, which keeps the mind active and counteracts the decline of the cognitive functions of the brain. This benefit results from keeping the brain active and having to concentrate during the session, an act which prevents cognitive and intellectual deterioration. This became evident when participants affirmed that they become mentally alert and tolerant as they adjusted to the singing, in tune with other colleagues, of the various parts in the chorus. 'It opens my mind and makes me become attentive to listen to those within my parts and the other parts as well', affirms Kwofie, a Level 300 B.Mus. student.

In social terms, sharing and connecting with other colleagues in singing provide important opportunities for socialising, meeting and interacting with others. Students are always brought together at mixed chorus sessions thereby giving individuals the opportunity to attract and be attracted to the enjoyment of singing as the texts of the songs provide 'imaginative play' and spiritual fulfilment to them. Through socialisation, participants had a feeling of contentment and security and sometimes got distracted from their medical conditions, thus making them feel physically and psychologically uplifted. A typical example is that of Sylvia whose predicament is quite pathetic but for whom the mixed chorus offers a supporting network of social relationships which alleviates her feelings of isolation and loneliness.

Physically, most students find singing an athletic activity that provides not only inner happiness and contentment but also internal peace, which consequently restores and rejuvenates their energy levels. It is true that singing involves deep controlled breathing, which counteracts anxiety. Deep breathing is likely to subdue anxiety and stress. Deep breathing involves an uninterrupted airflow, consistency of sound in all registers, phrasing and artistry, and all these have a positive effect on stress management. Mixed chorus involves a regular commitment to attend sessions scheduled within the week and that motivates people to avoid being physically inactive.

The study also reveals that singing can facilitate the improvement of health and wellbeing if some important generative mechanisms are put in place. It is therefore important that these mechanisms are stressed during singing at mixed chorus. This includes the articulation of chosen texts of the songs with emotionality. It is well articulated words with expressive diligence that yield a better understanding of the performance and needed emotional benefits of not only the performers but also the listeners. Emmons and Thomas (1998) comment thus on the singer's dilemma in terms of expressing emotionality:

The singer's indefatigable quest for a higher level of expression defines the basic elements of singing. They are two: the musical element of the voice (accurate, sustained vowels) and the expressive communication of speech (well-defined consonants). Singers and their teachers seek a diction that is as clear as speech. (p. 68)

Emmons and Thomas are of the view that clear diction in singing promotes good intonation, text comprehension and expressiveness in performance. Also, imagery-based exercises are relevant to vocal training to help participants develop and connect their minds and vocal capabilities to suit the intent of the composer. It is important to draw on the imagination in order to help the performer seamlessly integrate his or her understanding of the composer's intent and their own interpretive choices. These ideas always engage the mind and body towards feeling and eventually expressing emotion. As Jourdain (1997, p. 103) puts it, 'music interacts with 
the brain during listening, performance and understanding, culminating with the emotional aspect of music'. For example, singers can be made to articulate some text by imitating the breathing trend of someone who has just finished a sprint or marathon race. A child's cry or a dog's bark can be used as scenarios for imagery exercises which will have particular effects on emotional expression.

Loud speaking and exposure to background noise may strain the voices while incorrect posture may affect active singing and, for that reason, such musical practices should be avoided. This is why Gates, Forrest and Obert (2013) contend that:

most people, including singers, spend the majority of their vocal load speaking rather than singing. Singers' spoken voice should be well placed, supported, and free of strain on the vocal mechanism. They should review their speaking mannerisms so as to promote healthy every day voicing. Incorrect posture may cause disconnection with one's support mechanism, place undesired stress on the extrinsic musculature of the larynx thus affecting laryngeal height. (p. 24)

It is important that abuse of voices and incorrect postures are avoided in performance since sometimes, singers are not conscious of their posture during singing performances. Singers may also benefit from finding their optimal speaking pitch to avoid voice strains. Singing passages lying at the extremes of a singer's range, an octave higher or lower than marked, and singing entrances at audible levels can be a threat to the health of the voice (Miller, 1996, p. 95). Students should therefore know their limits. Likewise, trainers need to audition students for correct part placement in the mixed chorus. To deal with this problem, McKinney (1994) suggests that the hyperfunctional phonation/laryngeal tension must be checked. McKinney recommends some self-introspective prompts which I find meaningful: Is your voice classification too high? Is the singer singing too loud? Is the breath support locked? Is the posture tense/rigid? Are articulatory muscle hyperfunctional? Does the student have wrong vocal models? Is there tension from personality problems? Indeed, positive responses to these questions will definitely induce good singing habits to yield the desired therapeutic effects.

Though the study sought to investigate the positive benefits of the mixed chorus, it was revealed that contemporary pieces are not included in the songs selected for the mixed chorus. Furthermore, warm-ups during training sessions have not been effective because they do not conform to the techniques of the song chosen to be learnt. Exercises are overstretched with high pitches. Continuity of such practice may affect the vocal health of the singers. Warm-ups should appropriately suit the repertoire at hand. This is because the principle that lies behind the notion of warm-up or cooling down is similar to that of athletes needing to warm-up their bodies before daily practice to reduce injury (Miller, 1996). Miller is of the view that these exercises keep the body healthy because singing in itself cannot be done without good health.

Individuals are able to meld the psyche, intellect and emotions. Singing is meant to bring together the whole physical and spiritual being of a person. The benefits of mixed chorus surpass any other art form in respect of spiritual revitalisation, intellectual stimulation, and physical pleasure. Finally, singing requires of performers constant practice. In an academic institution like this, it is extremely hard to juggle both chorus sessions and other curricular commitments. However, constant practice will help the singers to be musically imaginative (Elliott, 1995).

\section{Conclusion}


The mixed chorus experience in many ways can serve as a mechanism for measuring and maintaining a sense of wellbeing. It appears that it can provide people with alternative solutions to everyday challenges, such as overcoming stress, maintaining an active physical and cognitive function, finding ways of remaining socially relevant and feeling less isolated. It is one of the most important ways to maintain physical health, psychological wellbeing, social activeness and cognitive sharpness because it also involves reading, at sight, unknown pieces in the course of training. It is, however, suggested that contemporary pieces be included in the musical repertoire to serve the interest of students who are into that genre. This study has proved that the mixed chorus experience has therapeutic benefits and enhances the wellbeing of all participants. If it is well executed with the associated generative mechanisms, the ramifications for health and wellbeing would be immense. Skills such as breathing, articulation and good posture, must be developed and established to create positive emotions, sharpen the brain and nurture we-feeling. When these are put in place, indeed, the mixed chorus experience will be one of the key factors of solving problems relating to health and wellbeing. 


\section{References}

Ahmet, K. (2015). Pre-service music teacher's opinions about the significance of choir lessons. Educational Research and Reviews, 10(7), 879-866.

Aldridge, D. (1996). Music therapy research and practice in medicine: From out of the silence. London: Jessica Kingsley.

Amuah, J. A., \& Acquah, E. O. (2013). Twenty five years of choral music Performance: Contribution of Winneba Youth Choir (WYC) in the Socio-Economic Development of Ghana. Research on Humanities and Social Sciences, 3(19), 105-112.

Andrews, G., Howie, P. M., Dozsa, M., \& Guitar, B. E. (1982). Stuttering: Speech pattern characteristics under fluency-inducing conditions. Journal of Speech and Hearing Research, 25, 208-216.

Bailey, B. A., \& Davidson, J. W. (2005). Effects of group singing and performance for marginalized and middle-class singers. Psychology of Music, 33(3), 269-303.

Bailey, B. A., \& Davidson, J. W. (2002). Adaptive characteristics of group singing: Perceptions from members of a choir for homeless men. Musicae Scientiae, 6(2), 221-256.

Biley, F. C. (2000). The effects on patient wellbeing of music listening as a nursing intervention: A review of the literature. Journal of Clinical Nursing, 9(5), 668-677.

Blacking, J., Byron, R., \& Nettl, B. (1995). Music, culture, and experience: Selected papers of John Blacking. Chicago: University of Chicago Press.

Blood, A. J., \& Zatorre, R. J. (2001). Intensely pleasurable responses to music correlate with activity in brain regions implicated in reward and emotion. Proceedings of the National Academy of Sciences of the United States of America, 98 (20), 11818-11823.

Bright, R. (1997). Wholeness in later life. London: Jessica Kingsley.

Bright, R. (1995). Music therapy as a factor in grief counselling. In T. Wigram, B. Saperston $\&$ R. West (Eds.), The art and science of music therapy: A handbook (pp. 309-323). Chur, Switzerland: Harwood Academic Publishers.

Bunt, L. (1996). Music therapy: An art beyond words. New York: Routledge.

Clift, S., Hancox, G., Morrison, I., Hess, B., Kreutz, G., \& Stewart, D. (2010). Choral singing and psychological wellbeing: Quantitative and qualitative findings from English choirs in a cross-national survey. Journal of Applied Arts \& Health, 1(1), 19-34.

Cohen, A., Bailey, B., \& Nilsson, T. (2002). The importance of music to seniors. Psychomusicology: A Journal of Research in Music Cognition, 18(89), 1-2.

Davidow ,J. H., Bothe , A. K., Andreatta ,R.D.,\& Ye, J. (2009). Measurement of phonated intervals during for fluency-inducing conditions. Journal Speech and Language Hearing Research, 52, 188-205.

Davis, W. (1999). Music therapy for mentally retarded children and adults. In Davis, W., Gfeller, K. and Thout, M. (Eds.), An introduction to music therapy: Theory and practice (pp. 133-163). Dubuque, IA: W.C. Brown.

Dillon, S. (2006). Assessing the positive influence of music activities in community development programs. Music Education Research, 8(2), 267-280.

Duffy, M. (2005). Performing identity within a multicultural framework. Social and Cultural Geography, 6 (5), 677-692.

Eguz, S. (1981). Choral training and direction. Ankara: Ayyildiz Press Inc.

Elliott, D. (1995). Music matters: A new philosophy of music education. Oxford: Oxford University Press. 
Emmons, S., \& Thomas, A. (1998). Power performance for singers: Transcending the barriers. Oxford: Oxford University Press.

Epp, J. (1987). Achieving health for all: A framework for health promotion. Canada, Ministry of Supply and Services.

Gates, R.L., Forrest, A., \& Obert, K. (2013). The owner's manual to the singer's voice. Oxford: Oxford University Press.

Hays, T., \& Minichiello, V. (2005). The meaning of music in the lives of older people: A qualitative study. Psychology of Music, 33(4), 437-451.

Healey, E. C., Mallard, A. R., \& Adams, M. R. (1976). Factors contributing to the reduction of stuttering during singing. Journal of Speech and Hearing Research, 19, 475-480.

Henfridsson, O., \& Bygstad, B. (2013). The generative mechanisms of digital infrastructure evolution. Mis Quarterly, 37(3), 907-931.

Jourdain, R. (1997). Music, the brain, and ecstasy: How music captures our imagination. New York: W. Morrow.

Kahn, A. (2001). Keeping the beat. Evanston, IL: Wordscope Associates.

Kenny, C. B. (1999). Beyond this point there be dragons: Developing general theory in music therapy. Nordic Journal of Music Therapy, 8(2), 127-136.

Kivy, P. (2001). New essays on musical understanding. Oxford: Clarendon.

Kotzab, H. (2005). The role and importance of survey research in the field of supply chain management. In Research methodologies in supply chain management (pp. 125-137). Physica-Verlag HD.

Kratus, J. (2007). Centennial series: Music education at the tipping point. Music Educators Journal, 94(2), 42-48.

Lipe, A.W. (2002). Beyond therapy: Music, spirituality, and health in human experience: A review of literature. Journal of Music Therapy, 39(3), 209-240.

Maranto, C. (1993). Applications of music in medicine. In M. Heal \& T. Wigram (Eds.), Music therapy in health education (pp. 153-174). London: Jessica Kingsley.

Marek, D. (2007). Singing: The first art. Plymouth: Scarecrow Press.

McKinney, J. (1994). The diagnosis and correction of vocal faults. Nashville: Genevox.

Miller, R. (1996). The structure of singing. Belmont: Wadsworth Group.

Rider, M. (1987). Treating chronic disease and pain with music-mediated imagery. The Arts in Psychotherapy, 14, 113-20.

Schorr, J. (1993). Music and pattern change in chronic pain. Advances in Nursing Sciences, 15(4), 27-36.

Schmutte, P. S., \& Ryff, C. D. (1997). Personality and well-being: Reexamining methods and meanings. Journal of Personality and Social Psychology, 73(3), 549-559.

Silber, L. (2005). Bars behind bars: The impact of a women's prison choir on social harmony. Music Education Research, 7(2), 251-271.

Small, C. (2011). Music, society, education. Middleton, CN: Wesleyan University Press.

Staricoff, R. L. (2004). Arts in health: A review of the medical literature. London: Arts Council England.

Schellenberg, E. G. (2012). Cognitive performance after listening to music: A review of the Mozart effect. In R. A. R. MacDonald, G. Kreutz, \& L. Mitchell (Eds.), Music, health, and wellbeing (pp. 324-338). Oxford \& New York: Oxford University Press.

Storr, A. (1992). Music and the mind. New York: Free Press. 
Tanur, L.M. (1982). Advances in methods for large-scale surveys and experiments. In R. Mcadams, N. J. Smelser, and D. J. Treiman (Eds.), Behavioral and social science research: A national resource, part II (pp. 65-96). Washington, DC: National Academy Press.

Tomatis, A. (1991). The conscious ear. New York: Station Hill Press.

Tsoukas, H. (1989). The validity of idiographic research explanations. Academy of Management Review, 14(4), 551-561.

Winter, M. J., Paskin, S., \& Baker, T. (1994). Music reduces stress and anxiety of patients in the surgical holding area. Journal of Post Anesthesia Nursing, 9(6), 340-343.

White, J. (1992). Music therapy: An intervention to reduce anxiety in the myocardial infarction patient. Clinical Nurse Specialist, 6(2), 58-63. 